\title{
PET-RAFT Facilitated 3D Printing of Polymeric Materials
}

Ali Bagheri ${ }^{\mathrm{a}, \mathrm{b}^{*}}$, Chris William Anderson Bainbridge ${ }^{\mathrm{a}}$, Kyle Edward Engel ${ }^{\mathrm{a}}$, Greg G. Qiao ${ }^{\mathrm{c}}$, Jiangtao $\mathrm{Xu}^{\mathrm{d}}$, Cyrille Boyer ${ }^{\mathrm{d}}$, and Jianyong Jin ${ }^{\mathrm{a}, \mathrm{b}}$

${ }^{a}$ School of Chemical Sciences, The University of Auckland, Auckland 1010, New Zealand

${ }^{\mathrm{b}}$ Dodd-Walls Centre for Quantum and Photonic Technologies, Auckland 1010, New Zealand ${ }^{\mathrm{c}}$ Department of Chemical Engineering, The University of Melbourne, Parkville, Victoria 3010, Australia ${ }^{d}$ Centre for Advanced Macromolecular Design (CAMD) and Australian Centre for NanoMedicine (ACN), School of Chemical Engineering, The University of New South Wales, Sydney NSW 2052, Australia

Email: ali.bagheri@auckland.ac.nz

Email: j.jin@auckland.ac.nz

KEYWORDS: 3D Printing, photoinduced electron-transfer (PET), Visible Light-Induced PET-RAFT Polymerization, Digital Light Processing

\begin{abstract}
Photopolymerization-based 3D printing process is typically conducted using nonliving free radical polymerization, which leads to fabrication of immutable materials. An alternative 3D printing of polymeric materials using trithiocarbonate (TTC) reversible addition-fragmentation chain transfer (RAFT) agents has always been a challenge for material and polymer scientists. Herein we report the first 3D printing of RAFTbased formulations that can be conducted fully open to air using standard digital light processing (DLP) 3D printer and under mild conditions of visible light at blue $\left(\lambda \max =483 \mathrm{~nm}, 4.16 \mathrm{~mW} / \mathrm{cm}^{2}\right)$ or green $(\lambda \max =$ $532 \mathrm{~nm}, 0.48 \mathrm{~mW} / \mathrm{cm}^{2}$ ) wavelength. Our approach is based on activation of TTC RAFT agents using eosin $\mathrm{Y}(\mathrm{EY})$ as a photoinduced electron-transfer (PET) catalyst in the presence of a reducing agent (tertiary amine), which facilitated oxygen tolerant 3D printing process via a reductive PET initiation mechanism. Re-activation of the TTCs present within the polymer networks enables post-printing monomer insertion into the outer layers of an already printed dormant object under second RAFT process, which provides a new pathway to design a more complex 3D printing. To our best knowledge, this is the first example of open-to-air PET-RAFT facilitated 3D printing of polymeric materials. We believe that our strategy is a significant step forward in the field of 3D printing.
\end{abstract}




\section{INTRODUCTION}

3D printing (also known as additive manufacturing) is a rapid emerging technology, which has revolutionized manufacturing industry to produce customized products. Contribution of polymer chemistry to the 3D printing technology has extended its scientific and technological impact and enabled a wide range of applications, such as drug delivery, tissue engineering, dentistry, microfluidic and etc. ${ }^{1,2,11,3-10}$ In particular, photopolymerization is a widely utilized technique in $3 \mathrm{D}$ printing. ${ }^{12-16}$ One shortcoming of photopolymerization-based 3D techniques is production of "dead" materials, due to the use of nonliving free radical polymerization. ${ }^{17,18}$ Although 3D printed shape memory polymers are capable of evolving their shape and property with time in response to an external stimulus, ${ }^{19-27}$ directly linking new polymers covalently from the surface of 3D printouts has not been achievable.

One promising approach to enable monomer insertion into an initially fabricated polymer networks ${ }^{28-31}$ or to fabricate dynamic polymer networks ${ }^{29,32-38}$, is by introduction of living functional groups such as trithiocarbonate (TTCs) iniferters- also known as reversible addition fragmentation chain transfer (RAFT) agents $^{39-45}$ into the strands of cross-linked networks. For instance, Johnson's group synthesized a gel network containing TTCs and demonstrated post-synthesis monomer insertion into these networks upon reactivation of TTC groups (under UV light). ${ }^{37}$ Followed by the advancements on the transformable polymer networks, Johnson and co-workers introduced the concept of living additive manufacturing, in which an initially fabricated TTC-containing gels (consist of strands bearing TTC iniferters) could undergo postsynthesis transformation using visible light photoredox catalysis. ${ }^{31,46}$ Recently, we $^{28}$ and Matyjaszewski's group $^{47}$ have exploited the iniferter process with TTC units ${ }^{33,48-55}$ present within photoexpandable/transformable-polymer networks (PET-PNs) to enable monomer insertion into crosslinked networks under visible light irradiation. Howerver, inteferter process under blue light irradiation is slow and reuqired deoxyination.

In this work, we propose to use a photoinduced electron-transfer RAFT (PET-RAFT) process without solvent in a 3D priting process. In general an efficient 3D printing process requires the following characteristics: (i) the presence of oxygen must not inhibit the polymerization reaction; and (ii) photopolymerization must be realized relatively with fast kinetics at room temperature. To develop a system that can be done fully open to air, an efficient oxygen tolerant photoRAFT system is demanded. Recently, oxygen tolerant reactions are rapidly moving to the forefront in polymerization systems to further extent the applicability of these systems and enable industrial viability. ${ }^{56-61}$ Thus far, different strategies have been exploited for achieving oxygen tolerant controlled radical polymerization systems: polymerizing through oxygen, ${ }^{59,60,62-64}$ enzyme mediated deoxygenation ${ }^{65-67}$ and the consumption of oxygen via a photoredox catalyst ${ }^{68-72}$; where the latter strategy is the most commonly used approach in photoRAFT systems. Photoredox catalysts with strong photoreducing nature, such as $\operatorname{Ir}(\mathrm{ppy})_{3},{ }^{73} \mathrm{Ru}(\mathrm{bpy})_{3} \mathrm{Cl}_{2},{ }^{74}$ eosin $\mathrm{Y}$ $(\mathrm{EY})^{43,75,76}$, and zinc tetraphenylporphine ${ }^{72,77,78}$ can convert triplet oxygen into a singlet oxygen which can 
be trapped by a singlet oxygen quencher and therefore enable oxygen tolerant systems; which has been known as PET-RAFT polymerization.

Furthermore, in recent years, there has been intense interest in using visible light in controlled radical polymerization systems ${ }^{79-88}$ and in 3D applications. ${ }^{11,16,18,89-94}$ This is due to the advantageous of using visible light sources (mainly light emitting diodes ((LEDs)) as compared to the UV lights; e.g. low-energy visible light sources are eco-friendly with low thermal effect and minimal side reaction, and are preferable for bio-related applications. ${ }^{18,95}$ In terms of 3D photopolymerization, visible light is also known for higher penetration depth that can facilitate higher 3D printing speed. Thus far, a number of visible light-sensitive photoinitiators that respond to light with longer wavelengths have been exploited to initiate the uncontrolled free radical-based 3D photopolymerization. ${ }^{12}$ Among different PET catalysts, EY- previously employed for PET-RAFT polymerization of (meth)acrylates, ${ }^{80,96}$ (meth)acrylamide ${ }^{43,75}$ and vinyl ketones ${ }^{97}$ - presents an interesting opportunity for 3D printing process fully open to air and under mild low energy visible light irradiation.

Herein, we report the first example of RAFT-based 3D printing process using EY as a photocatalyst, triethylamine (TEA) as a reducing agent and 4-cyano-4-[(dodecylsulfanylthiocarbonyl) sulfanyl] pentanoic acid (CDTPA) as a RAFT agent under PET-RAFT polymerization conditions. This design offers several advantages: (i) the polymerization can be mediated in a fully open to air system, and (ii) longer wavelength visible light can be utilized to activate the polymerization due to the strong absorption of EY in the long wavelength range (green light); and consequently (iii) it can accelerate 3D printing process by reaching higher penetration depth (Figure 1). A modified digital light processing (DLP) 3D printer equipped with blue $\left(\lambda \max =483 \mathrm{~nm}, 4.16 \mathrm{~mW} / \mathrm{cm}^{2}\right)$ or green $\left(\lambda_{\max }=532 \mathrm{~nm}, 0.48 \mathrm{~mW} / \mathrm{cm}^{2}\right)$ LED light was used. All 3D printings were conducted in open-to-air conditions with different formulations and printing parameters. Finally, the post-printing modification of the printed dormant objects via re-activation of the TTC within the objects enabled second RAFT process to modify the surface of the printed objects with new properties. 
a) Oxygen tolerant PET-RAFT facilitated 3D printing

- Photoredox Catalysis

- Open to Air $\left(\mathrm{O}_{2}\right)$

- $483 \mathrm{~nm}$ Blue LED

- $532 \mathrm{~nm}$ Green LED

- High Penetration Depth
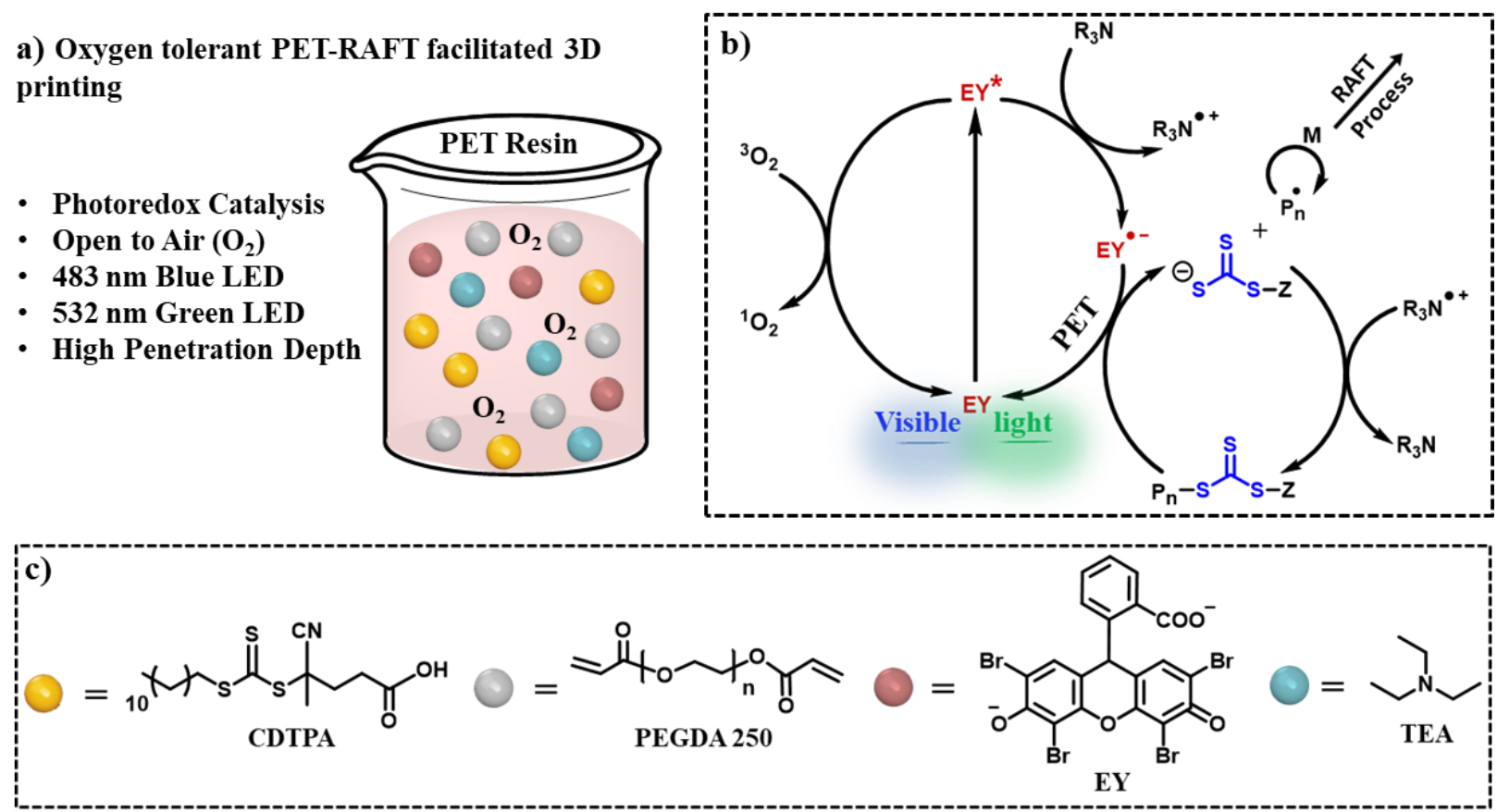

Figure 1. Method used to realize PET-RAFT facilitated 3D printing using photoredox catalysis conducted fully open to air, b) Proposed photopolymerization mechanism under visible light irradiation where the excited-state EY is reduced by a tertiary amine, leading to a reductive photoelectron transfer reversible addition-fragmentation chain transfer polymerization (PETRAFT). This mechanism has been previously reported in both solution ${ }^{80}$ and bulk ${ }^{97}$ controlled living radical polymerization for preparing linear polymers ${ }^{75}$. Although the degenerative chain transfer (RAFT process) in a highly crosslinked networks is extremely difficult, initiation mechanisms should follow the same pathways irrespective of the network formations. c) Chemical structures of 4-cyano-4-[(dodecylsulfanylthiocarbonyl) sulfanyl] pentanoic acid (CDTPA), poly(ethylene glycol) diacrylate (PEGDA, $M_{n}=250 \mathrm{~g} / \mathrm{mol}$ ), eosin Y (EY) and triethylamine (TEA) employed in this study.

\section{RESULTS AND DISCUSSION}

\subsection{Photoreactivity evaluations of the PET-RAFT based photocurable formulations using photo-} DSC

It has been reported that using EY involved a tertiary amine as a sacrificial reducing agent ${ }^{43,96}$ enables

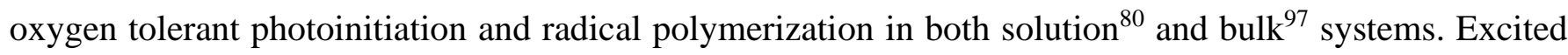
$\mathrm{EY}^{*}$ converts the triplet oxygen into the singlet oxygen via a photo-energy transfer process. ${ }^{56}$ Tertiary amine can act as an electron donor able to transfer electron to the excited $\mathrm{EY}^{*}$ to produce an $\mathrm{EY}$ radical anion $\left(\mathrm{EY}^{\bullet-}\right),{ }^{98}$ which can reduce the TTC by a PET process to generate a propagating carbon radical (Figure 1b). ${ }^{96}$ (We refer readers to few comprehensive studies on PET-RAFT mechanism ${ }^{43,75,76}$ ). In this work, we adopted the above mentioned EY/TEA system in combination with RAFT agent to prepare a visible lightcurable resin formulation without solvents. Our 3D printable PET-RAFT formulation contains the following ingredients: poly(ethylene glycol) diacrylate (PEGDA, $M_{\mathrm{n}}=250 \mathrm{~g} / \mathrm{mol}$ ), EY (photocatalyst), TEA (reducing agent) and CDTPA as RAFT agent. ${ }^{50-53,99}$ A photo-differential scanning calorimetry (photoDSC; 400-500 $\mathrm{nm}$ light source) was employed to evaluate the photoreactivity of the formulations with different feed ratios. As it can be seen from the recorded DSC signals in Figure 2a, iniferter-based formulation with $[$ PEGDA] $/[$ CDTPA] $=200: 1$ showed negligible heat flow within 16 min of 400-500 nm 
blue light irradiation, while addition of EY and TEA enabled faster photopolymerization rate within $t_{\max }=$ $\sim 3.8 \mathrm{~min}\left(t_{\max }\right.$ is the time to reach the maximum reaction rate which is an indication of the network formation $)^{100}$ These results confirm that the PET initiation pathway using EY/TEA is substantially faster than direct activation (photolysis) of TTC species under visible light irradiation, which were in agreement with previous studies $28,49,51,53,60,64,75,101$ (Figure 2). Furthermore, a control experiment was carried out to distinguish the PET-RAFT initiation pathway from free radical initiation in the absence of TTC; using combination of EY and tertiary amine. ${ }^{102,103}$ Slower photoinitiation and photopolymerization rate was observed when CDTPA was present in the formulations (Supporting Information, Figure S1) which confirms the activation of TTC units, corroborating other reports of using similar systems. ${ }^{75,80}$

To evaluate the effect of TTC on the photopolymerization rate, three molar ratios of [PEGDA]/[CDTPA] $(1000: 1,200: 1$ and 50:1) were tested $([$ PEGDA]/[CDTPA $] /[E Y] /[T E A]=(1000-50): 1: 100(\mathrm{ppm}): 1)$ (Figure 2b). Increasing the content of TTC species slows down the overall photopolymerization rate of PEGDA and delays the crosslinking process which might be in part due to the initiation and induced chain transfer reactions resulted from the TTC units (Figure 1b). In addition, the increase in the content of CDTPA results in the competition between light absorbance by EY and TTC, which might also explain the slower reaction rate in presence of CDTPA. ${ }^{104,105} \mathrm{We}$ further assessed the effects of EY concentration on the photopolymerization process. We fixed the molar ratio of PEGDA, CDTPA and TEA at 200:1:2 while the concentration of EY was varied from 10 to 400 ppm relative to the PEGDA monomer (Figure 2c). An increase in the photopolymerization process was observed by increasing the EY concentration from $10 \mathrm{ppm}$ to $200 \mathrm{ppm}$ showing $t_{\max }$ varying from $\sim 11.9 \mathrm{~min}$ to $\sim 3.9 \mathrm{~min}$. However, based on the photo-DSC results, increasing the EY concentration over $~ 300 \mathrm{ppm}$ (relative to PEGDA) resulted in a decrease in the photopolymerization rate (Figure 2c). This can be attributed to detrimental EY self-quenching processes, which might include triplet-triplet annihilation, excimer formation, and dye-dye electron transfer. ${ }^{106}$

We were also interested in the effect of TEA on the reactivity of the prepared formulations. As it can be seen from Figure 2d, increasing the amount of TEA relative to the CDTPA from 0.2 to 2 resulted in an increase in the photopolymerization rate. This increase in the reaction rate is due to the role of TEA to reduce the dissolved oxygen according to the mechanism presented in Figure 1b. For example, a formulation with a molar ratio of $[\mathrm{PEGDA}] /[\mathrm{CDTPA}] /[\mathrm{EY}] /[\mathrm{TEA}]=200: 1: 0.04: 2$ showed $t_{\max }$ of $\sim 2.8 \mathrm{~min}$ as compared to a [PEGDA]/[CDTPA]/[EY]/[TEA] $=200: 1: 0.04: 0.2$ formulation with a $t_{\max }$ of $\sim 12 \mathrm{~min}$. Further increase in the molar ratio of [TEA]/[CDTPA] (e.g. above 4) showed an insignificant effect on the photopolymerization rate. 

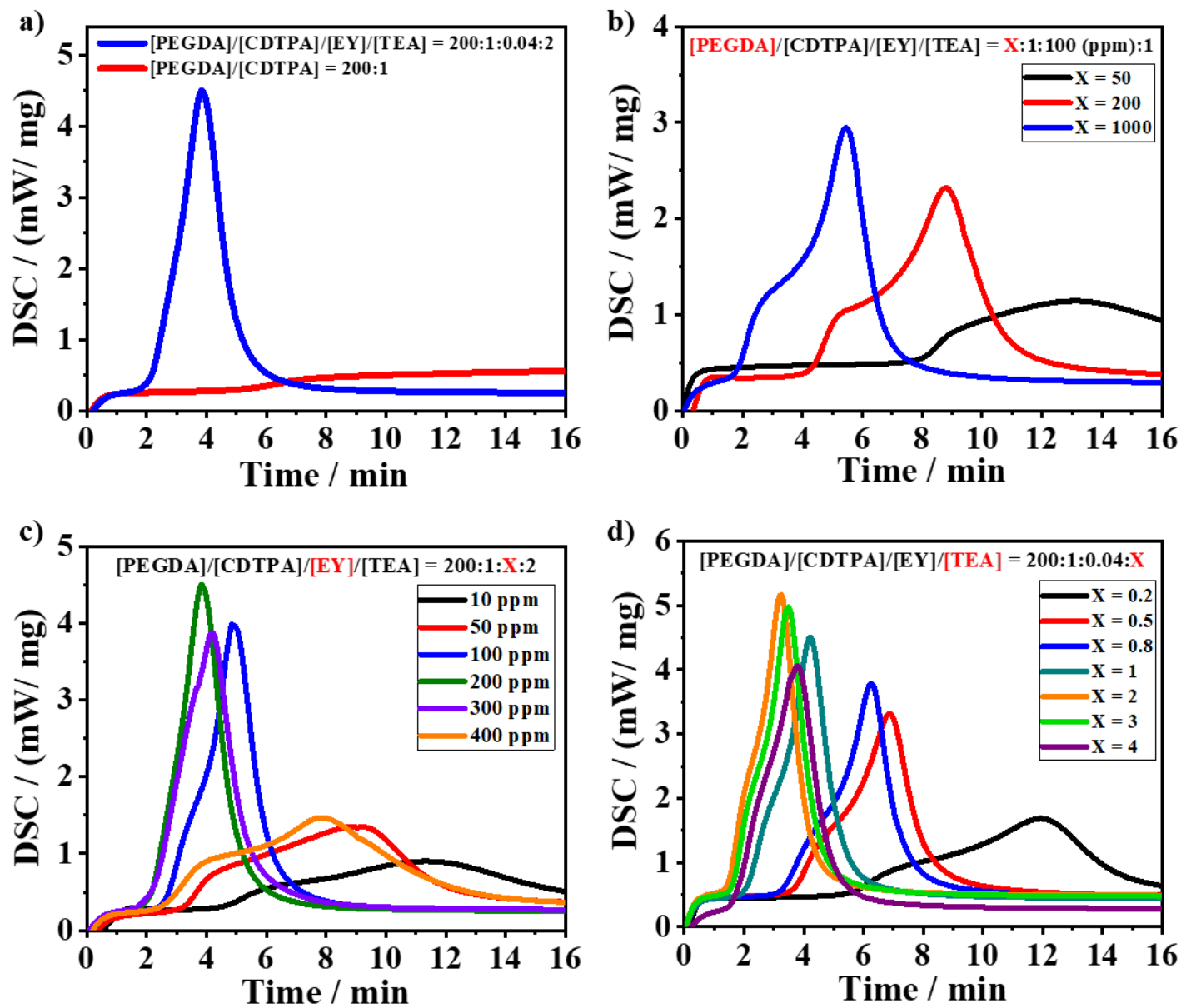

Figure 2. Photo-DSC plots of (a) PET-based and iniferter-based formulations, (b-d) PET-based formulations with different feed ratios and their effects on the ratE of photopolymerization/photocuring.

\subsection{D printing of the PET-RAFT based photocurable formulations under blue light}

Having demonstrated that PET initiation of TTC species under visible light facilitates faster photopolymerization rate as compared to the photolysis process and indeed offer tolerance to oxygen, we adopted EY/TEA-based resin formulations to investigate the printability of this formulation fully open to air. To demonstrate this, we first modified a bottom-up DLP printer where blue LED lights $(\lambda \max =483$ $\mathrm{nm}, 4.16 \mathrm{~mW} / \mathrm{cm}^{2}$ ) were focused on the bottom surface of the resin vat (Figure 3). The emission spectrum of the blue LED source was measured, showing some emission-absorption overlap with EY catalyst (Figure 3a). The 3D printing was then carried out in a layer-by-layer process by digital slicing software with pre-defined parameters. To begin with, a PET formulation with molar ratio of $[\mathrm{PEGDA}] /[\mathrm{CDTPA}] /[\mathrm{EY}] /[\mathrm{TEA}]=200: 1: 0.04: 3$ was prepared $(\mathrm{PET} 3 \mathrm{D}-1$; Figure 3d), while the printing variables were set at: exposure (curing) times of 8 min per layer and layer thickness of $100 \mu \mathrm{m}$. Build speed of $430 \mu \mathrm{m} / \mathrm{h}$ was achieved using this processing parameters. We further attempted to lower the exposure time to 5 min, while keeping other parameters constant (PET 3D -2); which resulted in a higher build speed of $730 \mu \mathrm{m} / \mathrm{h}$. 
Printability of a different PET-RAFT formulation with a molar ratio of [PEGDA $] /[\mathrm{CDTPA}] /[\mathrm{EY}] /[\mathrm{TEA}]=$ 50:1:0.01:3 was also studied by varying the processing parameters. For instance, 5 min exposure time per $100 \mu \mathrm{m}$ layer (PET 3D -3, Figure 3d) and $20 \mu \mathrm{m}$ layer (PET 3D -4, Figure 3d) resulted in build speeds of $658 \mu \mathrm{m} / \mathrm{h}$ and $138 \mu \mathrm{m} / \mathrm{h}$ respectively. A relative high build speed was obtained despite the presence of air. We also attempted to reduce the exposure time to 3 min per $20 \mu \mathrm{m}$ (PET 3D -5, Figure 3d) which resulted in a build speed of $282 \mu \mathrm{m} / \mathrm{h}$. Nevertheless, $3 \mathrm{~min}$ exposure time was not sufficient to photopolymerize/solidify $200 \mu \mathrm{m}$ layer (PET 3D-6, Figure 3d) to obtain adequate adhesion to the build platform. To enable 3D printing of $[\mathrm{PEGDA}] /[\mathrm{CDTPA}] /[\mathrm{EY}] /[\mathrm{TEA}]=50: 1: 0.01: 3$ formulation with 200 $\mu \mathrm{m}$ layer thickness, $8 \mathrm{~min}$ of blue LED $\left(\lambda \max =483 \mathrm{~nm}, 4.16 \mathrm{~mW} / \mathrm{cm}^{2}\right)$ light was required (PET 3D-7, Figure 3d). These results confirm that our PET formulations are efficient and robust. A microscope image of the printed object's cross section clearly shows uniform stacked layers of the printed object. To further determine the printing fidelity, scanning electron microscopy (SEM) was used to acquire image of the printed object; which confirmed layer-by-layer process with outstanding layer thickness uniformity Interestingly, the layer thicknesses were in good agreement with the predefined values using slicing software (Figure 3e).
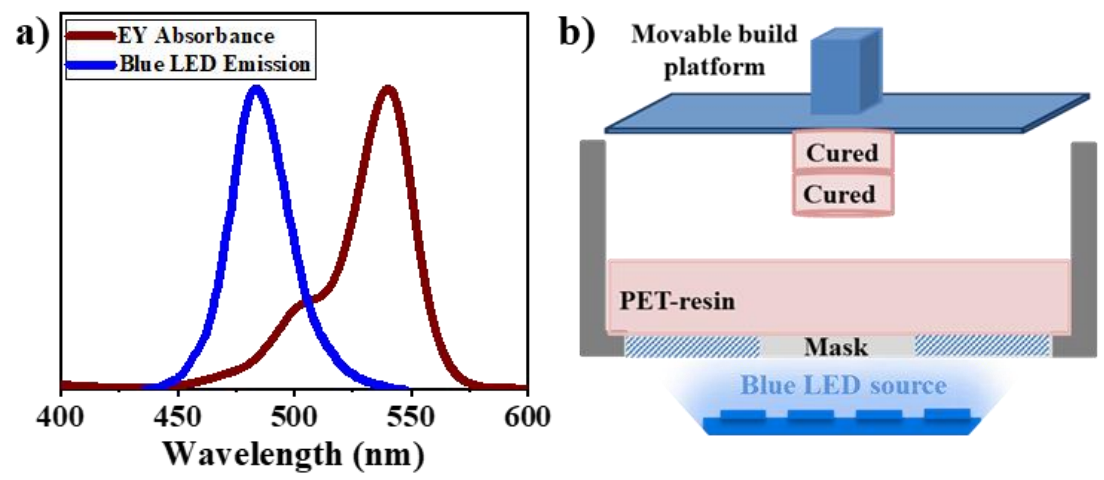

d)

\begin{tabular}{ccccc}
\hline Entry & $\begin{array}{c}\text { [PEGDA]/[CDTPA] } \\
\text { /[EY]/[TEA] }\end{array}$ & $\begin{array}{c}\text { Exposure } \\
\text { time per } \\
\text { layer }(\mathbf{m i n})\end{array}$ & $\begin{array}{c}\text { a } \\
\text { Target layer } \\
\text { thickness } \\
(\boldsymbol{\mu m})^{\mathbf{a}}\end{array}$ & $\begin{array}{c}\text { Actual } \\
\text { build speed } \\
(\boldsymbol{\mu m} / \mathbf{h})\end{array}$ \\
\hline bET 3D-1 & $200: 1: 0.04: 3$ & 8 & 100 & 430 \\
PET 3D -2 & $200: 1: 0.04: 3$ & 5 & 100 & 730 \\
PET 3D -3 & $50: 1: 0.01: 3$ & 5 & 100 & 658 \\
PET 3D -4 & $50: 1: 0.01: 3$ & 5 & 20 & 138 \\
PET 3D -5 & $50: 1: 0.01: 3$ & 3 & 20 & 282 \\
PET 3D -6 & $50: 1: 0.01: 3$ & 3 & 200 & - \\
PET 3D -7 & $50: 1: 0.01: 3$ & 8 & 200 & 819 \\
\hline
\end{tabular}

c)
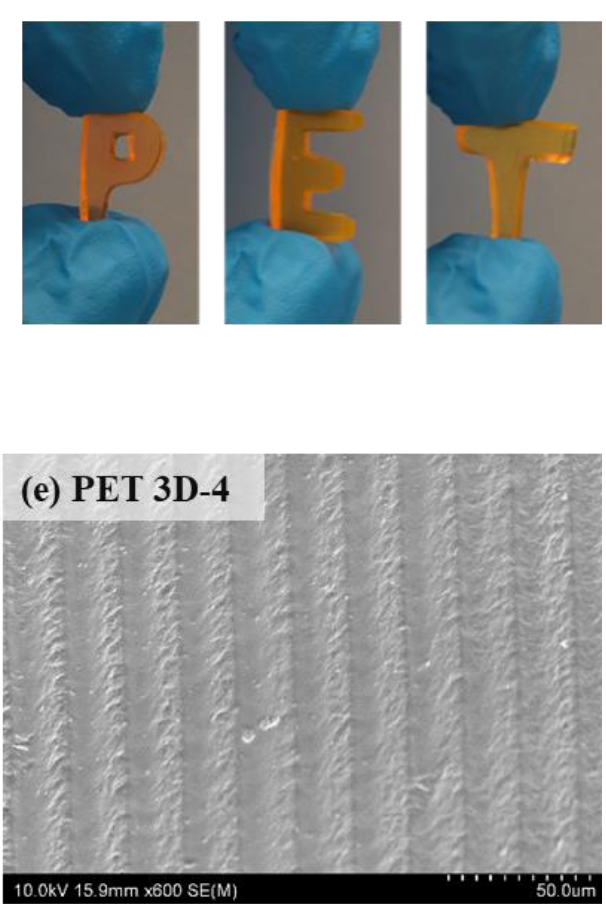

Figure 3. (a) UV-vis absorption spectrum of EY and the emission spectrum of the in house build blue LED light source of 3D printer, showing emission-absorption overlap (both spectra are normalized), (b) Schematic of 3D printing process using a modified bottom-up DLP printer equipped with blue LED lights $\lambda$ max $=483 \mathrm{~nm}, 4.16 \mathrm{~mW} / \mathrm{cm}^{2}$, at room temperature and fully open to air (inset shows an optical image of a 3D object printed using PET 3D-1 formulations and processing conditions), (c) Optical images of "PET" letters (note that these letters were printed under green light irradiation-refer to PET 3D-10 in Figure

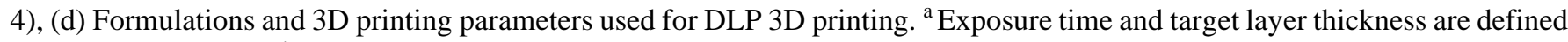
by a slicing software. ${ }^{b}$ The actual build speed is based on the final thickness achieved over time and (e) A representative SEM image showing the stacked layers from a cross sectional view of the printed object. 


\subsection{D printing of the PET-RAFT based photocurable formulations under green light}

Recently, Sumerlin, Boyer and co-workers elucidated the mechanism of PET-RAFT solution polymerization using EY involved a tertiary amine, in which blue light irradiation resulted in a multiple initiation mechanism and reversible-termination steps. ${ }^{75,80}$ The study showed that use of green light enables mainly PET pathways and limits other possible initiation mechanisms (e.g., photoiniferter and tertiary amine reduction mechanisms). Therefore, using lower energy green light over blue light could enable only PET pathway and will pose less challenges during 3D printing of sensitive systems such as biomaterials. ${ }^{43}$ To this end, we modified our 3D printer and used green LED light $\left(\lambda \max =532 \mathrm{~nm}, 0.48 \mathrm{~mW} / \mathrm{cm}^{2}\right)$ to perform 3D printing processes based on solely reductive PET pathway initiation. EY which has a high molar extinction coefficients at high wavelength $\left(\lambda_{\max }^{a b s}=543 \mathrm{~nm}\right)$ showed a good overlap with the emission spectrum of the commercial green LEDs $\left(\lambda_{\max }=532 \mathrm{~nm}, 0.48 \mathrm{~mW} / \mathrm{cm}^{2}\right)$ (Figure 4a). Initially, a PET formulation using a $[\mathrm{PEGDA}] /[\mathrm{CDTPA}] /[\mathrm{EY}] /[\mathrm{TEA}]=200: 1: 0.04: 3$ was used in a printing process with 8 min exposure per $100 \mu \mathrm{m}$ layer. The layer-by-layer 3D printing process was successful, in which a build speed of $528 \mu \mathrm{m} / \mathrm{h}$ was obtained (PET 3D-8; Figure 4b). As compared to its alike blue LED based printing process (PET 3D-1, Figure 3d), green LED light resulted in an even higher build speed despite its lower intensity ( $\sim 10$ fold). As it can be seen from Figure $4 \mathbf{b}$, various formulations and 3D printing parameters were also tested, showing a similar trend as blue LED based printing processes; while in all cases, green LED light resulted in a higher build speed. We summaries this outcome resulted from: (i) better absorbanceemission overlap between EY and green LED emission, (ii) less contribution of homolytic photolysis to PET initiation ${ }^{75}$ and (iii) higher penetration depth of green light as compared to the blue light ${ }^{53}$. To confirm higher penetration of green light over blue light, we carried out a curing depth measurement. A mask with a circular area $(\mathrm{d}=1 \mathrm{~cm})$ was used in a modified DLP 3D printer which was exposed to blue $(\lambda$ max $=483$ $\left.\mathrm{nm}, 4.16 \mathrm{~mW} / \mathrm{cm}^{2}\right)$ or green $\left(\lambda \max =532 \mathrm{~nm}, 0.48 \mathrm{~mW} / \mathrm{cm}^{2}\right)$ LED light for $12 \mathrm{hr}$. The cured discs were then removed from the vat and their thicknesses were measured. The light penetration depths for the blue and green corresponding energy dose were $0.64 \mathrm{~mm}$ and $1.23 \mathrm{~mm}$ respectively. Furthermore, to demonstrate the uniform stacked layers of the printed object, an optical image and a microscope image of a 3D object (printed using PET 3D-8 formulations and processing conditions) are presented in Figure 4c. SEM images of the representative printed objects further confirmed a layer-by-layer process with extremely high accuracy in layer uniformity and thickness (Figure 4d-g). 


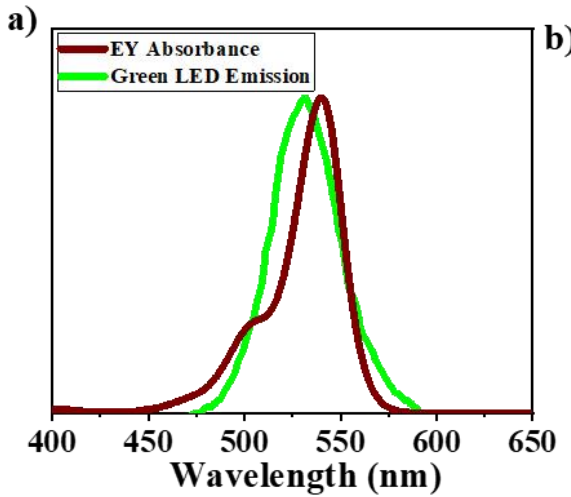

\begin{tabular}{lcccc}
\hline bntry & $\begin{array}{c}\text { [PEGDA]/[CDTPA]/ } \\
{[\mathbf{E Y}] /[\mathrm{TEA}]}\end{array}$ & $\begin{array}{c}\text { Exposure } \\
\text { time per layer } \\
(\mathbf{m i n}) \mathbf{a}\end{array}$ & $\begin{array}{c}\text { Target layer } \\
\text { thickness } \\
(\boldsymbol{\mu m})^{\mathbf{a}}\end{array}$ & $\begin{array}{c}\text { Actual } \\
\text { build speed } \\
(\boldsymbol{\mu m} / \mathbf{h})^{\mathbf{b}}\end{array}$ \\
\hline PET 3D -8 & $200: 1: 0.04: 3$ & 8 & 100 & 528 \\
PET 3D -9 & $200: 1: 0.04: 3$ & 5 & 100 & 816 \\
PET 3D -10 & $50: 1: 0.01: 3$ & 8 & 100 & 746 \\
PET 3D -11 & $50: 1: 0.01: 3$ & 5 & 20 & 243 \\
PET 3D -12 & $50: 1: 0.01: 3$ & 3 & 20 & 332 \\
PET 3D -13 & $50: 1: 0.01: 3$ & 3 & 200 & - \\
PET 3D -14 & $50: 1: 0.01: 3$ & 8 & 200 & 1354 \\
\hline
\end{tabular}

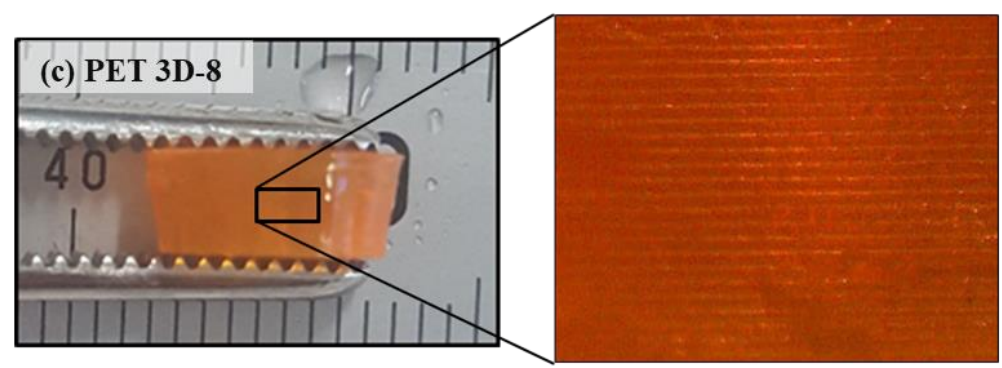

(d) PET 3D-8
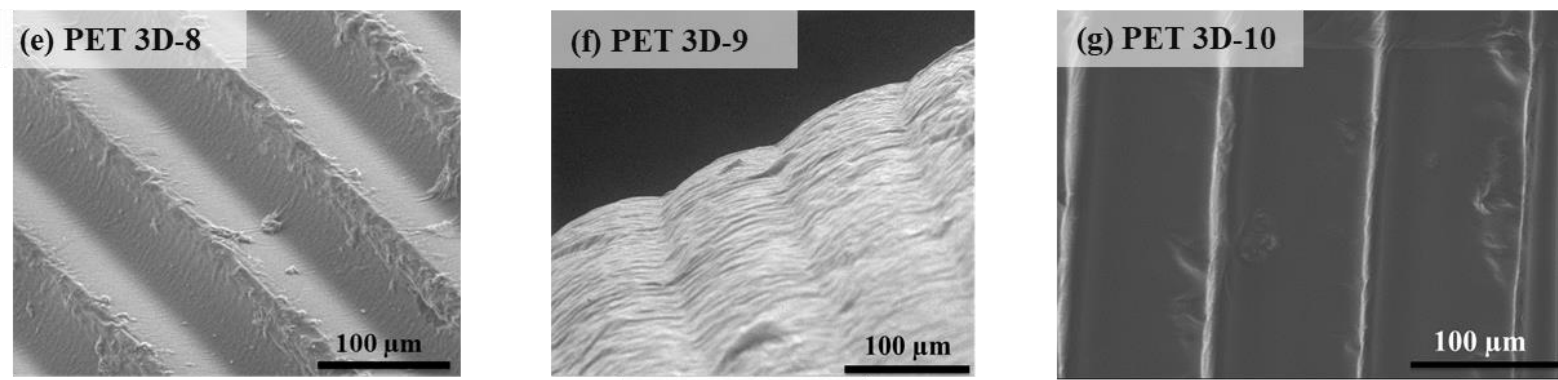

Figure 4. (a) UV-vis absorption spectrum of EY and the emission spectrum of the in house build green LED light source of 3D printer, showing emission-absorption overlap (both spectra are normalized), (b) Formulations and 3D printing parameters used for DLP 3D printing using a modified bottom-up DLP printer equipped with green LED $\left(\lambda_{\max }=532 \mathrm{~nm}, 0.48 \mathrm{~mW} / \mathrm{cm}^{2}\right)$, at room temperature and fully open to air. ${ }^{a}$ Exposure time and target layer thickness are defined by a slicing software. ${ }^{\mathrm{b}}$ The actual build speed is based on the final thickness achieved over time. (c) An optical image and a microscope image of a 3D object printed using PET 3D-8 formulations and processing conditions. (d-g) Representative SEM images showing the stacked layers from a cross sectional view of the printed objects.

\subsection{Post-printing modification of the 3D printed objects}

Having shown that our PET-RAFT-based formulations can be effectively utilized in a 3D printing process, we then studied whether the TTC units present within the 3D printed objects could be re-activated to either inset new monomers into an already printed object or chain extended on its surface. To achieve this, we first 3D printed an object using a formulation and printing conditions as PET 3D-10 (Figure 4b), where additional $n$-butyl acrylate (BA) and PEGDA $6000\left(M_{\mathrm{n}}=6000 \mathrm{~g} / \mathrm{mol}\right)$ were added and CDTPA was replaced with a dibenzyl trithiocarbonate (DBTTC) RAFT agent (monomer to RAFT ratio of [OEGDA 250]: [OEGDA 6000]: [BA]: [DBTTC] = 45:0.04:4:1). The BA co-monomer was used to reduce the glass transition temperature $\left(T_{\mathrm{g}}\right)$ value of the printed materials and thus facilitate high chain mobility for the enhancement of monomer diffusion into the network and subsequent monomer insertion process. ${ }^{107}$ The PEGDA 6000 was also used in order to obtain higher swelling capacity and therefore enable better monomer diffusion into the networks. However, due to low solubility of PEGDA 6000, we were not able 
to increase its ratio to PEGDA 250. The addition of PEGDA 6000 resulted in a slight increase in the swelling ratio (from $\sim 1.08$ to $\sim 1.4$ ) as compared to its counterpart object without PEGDA 6000. Swelling ratio defined as $W_{w} / W_{d}$, where $W_{w}$ is the weight of a sample swollen in DMSO; $W_{d}$ is the weight of sample in the dry state. Indeed symmetric DBTTC was used due to its ability in post-synthesis monomer insertion into highly crosslinked networks. ${ }^{28}$ The new formulation was proved to be as effective as previous formulations in a 3D printing process. The object was then soaked into a "growth medium" containing a hydrophobic BA monomer dissolved in DMSO. Subsequently, a blue LED light $(\lambda \max =460 \mathrm{~nm}, 0.7$ $\mathrm{mW} / \mathrm{cm}^{2}$ ) was employed to reactivate the dormant DBTTC units within the printed object via an iniferter RAFT polymerization mechanism. The final modified 3D object was studied by water contact angle measurements. The average contact angle of the modified object increased from $32.8^{\circ}$ to $68.1^{\circ}$ compared to its original surface, confirming an increase in hydrophobicity resulted from increased poly(BA) on the surface (Figure 5). We believe that due to the high crosslinking density of the $3 \mathrm{D}$ printed materials, the formed pBA are mostly rope-shaped brushes for the outer layers of the modified object. ${ }^{28}$

a)

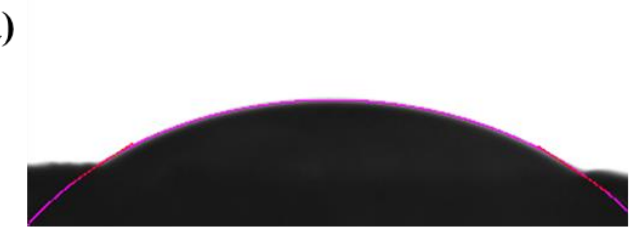

Post-Printing BA

Monomer Insertion

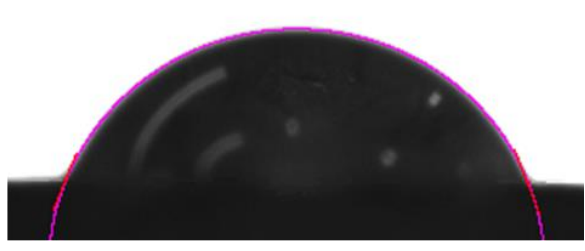

b)

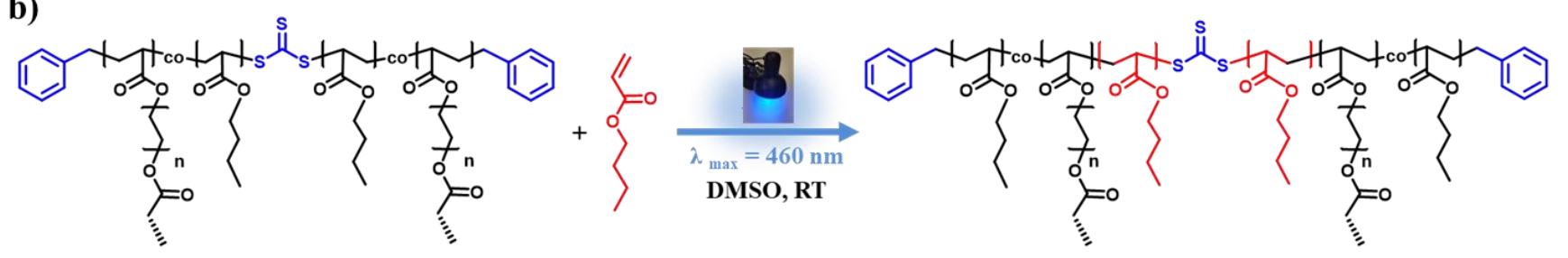

Figure 5. (a) Water contact angles of an initially printed object and its subsequent modified network after BA insertion; and (b) Reaction scheme of the post-printing BA insertion. Polymerization of BA or in another word, BA monomer insertion into the printed objects was performed under blue LED light $\left(\lambda \max =460 \mathrm{~nm}, 0.7 \mathrm{~mW} / \mathrm{cm}^{2}\right)$, without presence of external initiators or catalysts. Note that for simplicity, PEGDA 250 and PEGDA 6000 are presented as one polymer segment in the scheme presented here. 


\section{CONCLUSION}

We report the first fully open to air PET-RAFT 3D printing process of polymeric materials. Our strategy is based on activation of TTC RAFT agents using EY as a PET catalyst in the presence of a TEA as a sacrificial and reducing agent. The EY/TEA system enabled oxygen tolerant 3D printing process via a reductive PET initiation mechanism under mild conditions of either blue $\left(\lambda_{\max }=483 \mathrm{~nm}, 4.16 \mathrm{~mW} / \mathrm{cm}^{2}\right)$ or green $\left(\lambda_{\max }=532 \mathrm{~nm}, 0.48 \mathrm{~mW} / \mathrm{cm}^{2}\right)$ LED light irradiation in a DLP printer. The advantage of using green light over blue light is higher light penetration depth and thus faster 3D printing process. The utility and versatility of our PET-3D approach was demonstrated using a variety of processing parameters and formulations. Re-activation of TTC species within the 3D printed objects allow post-printing monomer insertion into an already printed dormant object. Our strategy addresses two major challenges in 3D printing using controlled polymerization methods: oxygen tolerance and fast printing speed. We believe the contribution of this paper is a significant step forward in the field of complex 3D printing.

\section{ASSOCIATED CONTENT}

\section{Supporting Information}

The following files are available in the Supporting Information: chemicals, characterizations, experimental procedures and additional DSC results (PDF).

\section{AUTHOR INFORMATION}

\section{Corresponding Author}

*E-mail: ali.bagheri@auckland.ac.nz

*E-mail: j.jin@auckland.ac.nz

\section{Conflicts of interest}

The authors declare no competing financial interest.

\section{Acknowledgement}

$\mathrm{JJ}$ and $\mathrm{AB}$ would like to thank the New Zealand Ministry of Business, Innovation and Employment (MBIE) Endeavour Fund for funding the Advanced Laser Microfabrication for NZ Industries research programme (UOAX-1701). 


\section{REFERENCES}

(1) Jungst, T.; Smolan, W.; Schacht, K.; Scheibel, T.; Groll, J. Strategies and Molecular Design Criteria for 3D Printable Hydrogels. Chem. Rev. 2016, 116, 1496-1539.

(2) Wang, M. O.; Vorwald, C. E.; Dreher, M. L.; Mott, E. J.; Cheng, M. H.; Cinar, A.; Mehdizadeh, H.; Somo, S.; Dean, D.; Brey, E. M.; et al. Evaluating 3D-Printed Biomaterials as Scaffolds for Vascularized Bone Tissue Engineering. Adv. Mater. 2014, 27, 138-144.

(3) Zorlutuna, P.; Jeong, J. H.; Kong, H.; Bashir, R. Stereolithography-Based Hydrogel Microenvironments to Examine Cellular Interactions. Adv. Funct. Mater. 2011, 21, 3642-3651.

(4) Shukrun, E.; Cooperstein, I.; Magdassi, S. 3D-Printed Organic-Ceramic Complex Hybrid Structures with High Silica Content. Adv. Sci. 2018, 5, 1-7.

(5) Feng, C.; Zhang, W.; Deng, C.; Li, G.; Chang, J.; Zhang, Z.; Jiang, X.; Wu, C. 3D Printing of Lotus Root-Like Biomimetic Materials for Cell Delivery and Tissue Regeneration. Adv. Sci. 2017, 4, 1700401 .

(6) Pati, F.; Gantelius, J.; Svahn, H. A. 3D Bioprinting of Tissue/Organ Models. Angew. Chemie - Int. Ed. 2016, 55, 4650-4665.

(7) Seidler, K.; Griesser, M.; Kury, M.; Harikrishna, R.; Dorfinger, P.; Koch, T.; Svirkova, A.; Marchetti-Deschmann, M.; Stampfl, J.; Moszner, N.; et al. Vinyl Sulfonate Esters: Efficient Chain Transfer Agents for the 3D Printing of Tough Photopolymers without Retardation. Angew. Chemie - Int. Ed. 2018, 57, 9165-9169.

(8) Wang, J.; Chiappone, A.; Roppolo, I.; Shao, F.; Fantino, E.; Lorusso, M.; Rentsch, D.; Dietliker, K.; Pirri, C. F.; Grützmacher, H. All-in-One Cellulose Nanocrystals for 3D Printing of Nanocomposite Hydrogels. Angew. Chemie - Int. Ed. 2018, 57, 2353-2356.

(9) Corrigan, N.; Yeow, J.; Judzewitsch, P.; Xu, J.; Boyer, C. Seeing the Light: Advancing Materials Chemistry through Photopolymerization. Angew. Chemie - Int. Ed. 2019, 58, 5170-5189.

(10) Zarek, M.; Layani, M.; Cooperstein, I.; Sachyani, E.; Cohn, D.; Magdassi, S. 3D Printing of Shape Memory Polymers for Flexible Electronic Devices. Adv. Mater. 2016, 28, 4449-4454.

(11) Wang, J.; Stanic, S.; Altun, A. A.; Schwentenwein, M.; Dietliker, K.; Jin, L.; Stampfl, J.; Baudis, S.; Liska, R.; Grützmacher, H. A Highly Efficient Waterborne Photoinitiator for Visible-Light-Induced Three-Dimensional Printing of Hydrogels. Chem. Commun. 2018, 54, 920-923.

(12) Bagheri, A.; Jin, J. Photopolymerization in 3D Printing. ACS Appl. Polym. Mater. 2019, 1, 593-611.

(13) Ligon, S. C.; Liska, R.; Stampfl, J.; Gurr, M.; Mülhaupt, R. Polymers for 3D Printing and Customized Additive Manufacturing. Chem. Rev. 2017, 117, 10212-10290.

(14) Layani, M.; Wang, X.; Magdassi, S. Novel Materials for 3D Printing by Photopolymerization. Adv. Mater. 2018, 30, 1-7.

(15) Zhang, J.; Xiao, P. 3D Printing of Photopolymers. Polym. Chem. 2018, 9, 1530-1540.

(16) Al Mousawi, A.; Poriel, C.; Dumur, F.; Toufaily, J.; Hamieh, T.; Fouassier, J. P.; Lalevée, J. Zinc Tetraphenylporphyrin as High Performance Visible Light Photoinitiator of Cationic Photosensitive Resins for LED Projector 3D Printing Applications. Macromolecules 2017, 50, 746-753.

(17) Fu, J.; Yin, H.; Yu, X.; Xie, C.; Jiang, H.; Jin, Y.; Sheng, F. Combination of 3D Printing Technologies and Compressed Tablets for Preparation of Riboflavin Floating Tablet-in-Device (TiD) Systems. Int. J. Pharm. 2018, 549, 370-379.

(18) Zhang, J.; Dumur, F.; Xiao, P.; Graff, B.; Bardelang, D.; Gigmes, D.; Fouassier, J. P.; Lalevée, J. Structure Design of Naphthalimide Derivatives: Toward Versatile Photoinitiators for Near- 
UV/Visible LEDs, 3D Printing, and Water-Soluble Photoinitiating Systems. Macromolecules 2015, 48, 2054-2063.

(19) Sydney Gladman, A.; Matsumoto, E. A.; Nuzzo, R. G.; Mahadevan, L.; Lewis, J. A. Biomimetic 4D Printing. Nat. Mater. 2016, 15, 413-418.

(20) Momeni, F.; M.Mehdi Hassani.N, S.; Liu, X.; Ni, J. A Review of 4D Printing. Mater. Des. 2017, $122,42-79$.

(21) Yang, H.; Leow, W. R.; Wang, T.; Wang, J.; Yu, J.; He, K.; Qi, D.; Wan, C.; Chen, X. 3D Printed Photoresponsive Devices Based on Shape Memory Composites. Adv. Mater. 2017, 29, 1701627.

(22) Kotikian, A.; Truby, R. L.; Boley, J. W.; White, T. J.; Lewis, J. A. 3D Printing of Liquid Crystal Elastomeric Actuators with Spatially Programed Nematic Order. Adv. Mater. 2018, 30, 1-6.

(23) Dutta, S.; Cohn, D. Temperature and PH Responsive 3D Printed Scaffolds. J. Mater. Chem. B 2017, 5, 9514-9521.

(24) Roppolo, I.; Chiappone, A.; Angelini, A.; Stassi, S.; Frascella, F.; Pirri, C. F.; Ricciardi, C.; Descrovi, E. 3D Printable Light-Responsive Polymers. Mater. Horizons 2017, 4, 396-401.

(25) Zhao, Z.; Kuang, X.; Yuan, C.; Qi, H. J.; Fang, D. Hydrophilic/Hydrophobic Composite ShapeShifting Structures. ACS Appl. Mater. Interfaces 2018, 10, 19932-19939.

(26) Gao, B.; Yang, Q.; Zhao, X.; Jin, G.; Ma, Y.; Xu, F. 4D Bioprinting for Biomedical Applications. Trends Biotechnol. 2016, 34, 746-756.

(27) Lendlein, A.; Jiang, H.; Junger, O.; Langer, R. Light-Induced Shape-Memory Polymers. Nature 2005, 434, 879-882.

(28) Bagheri, A.; Bainbridge, C.; Jin, J. Visible Light-Induced Transformation of Polymer Networks. ACS Appl. Polym. Mater. 2019, 1, 1896-1904.

(29) Lampley, M. W.; Harth, E. Photocontrolled Growth of Cross-Linked Nanonetworks. ACS Macro Lett. 2018, 7, 745-750.

(30) Lampley, M.; Tsogtgerel, E.; Harth, E. M. Nanonetwork Photogrowth Expansion: Tailoring Nanoparticle Networks' Chemical Structure and Local Topology. Polym. Chem. 2019, 10, 37993924.

(31) Chen, M.; Gu, Y.; Singh, A.; Zhong, M.; Jordan, A. M.; Biswas, S.; Korley, L. T. J.; Balazs, A. C.; Johnson, J. A. Living Additive Manufacturing: Transformation of Parent Gels into Diversely Functionalized Daughter Gels Made Possible by Visible Light Photoredox Catalysis. ACS Cent. Sci. 2017, 3, 124-134.

(32) Gordon, M. B.; French, J. M.; Wagner, N. J.; Kloxin, C. J. Dynamic Bonds in Covalently Crosslinked Polymer Networks for Photoactivated Strengthening and Healing. Adv. Mater. 2015, 27, 8007-8010.

(33) Amamoto, Y.; Otsuka, H.; Takahara, A.; Matyjaszewski, K. Self-Healing of Covalently CrossLinked Polymers by Reshuffling Thiuram Disulfide Moieties in Air under Visible Light. Adv. Mater. 2012, 24, 3975-3980.

(34) Nicolaÿ, R.; Kamada, J.; Van Wassen, A.; Matyjaszewski, K. Responsive Gels Based on a Dynamic Covalent Trithiocarbonate Cross-Linker. Macromolecules 2010, 43, 4355-4361.

(35) Amamoto, Y.; Kamada, J.; Otsuka, H.; Takahara, A.; Matyjaszewski, K. Repeatable Photoinduced Self-Healing of Covalently Cross-Linked Polymers through Reshuffling of Trithiocarbonate Units. Angew. Chemie - Int. Ed. 2011, 50, 1660-1663.

(36) Amamoto, Y.; Otsuka, H.; Takahara, A.; Matyjaszewski, K. Changes in Network Structure of Chemical Gels Controlled by Solvent Quality through Photoinduced Radical Reshuffling Reactions of Trithiocarbonate Units. ACS Macro Lett. 2012, 1, 478-481. 
(37) Zhou, H.; Johnson, J. A. Photo-Controlled Growth of Telechelic Polymers and End-Linked Polymer Gels. Angew. Chemie - Int. Ed. 2013, 52, 2235-2238.

(38) Singh, A.; Kuksenok, O.; Johnson, J. A.; Balazs, A. C. Tailoring the Structure of Polymer Networks with Iniferter-Mediated Photo-Growth. Polym. Chem. 2016, 7, 2955-2964.

(39) Boyer, C.; Bulmus, V.; Davis, T. P.; Ladmiral, V.; Liu, J.; Perrier, S. Bioapplications of RAFT Polymerization. Chem. Rev. 2009, 109, 5402-5436.

(40) Moad, G.; Rizzardo, E.; Thang, S. H. Radical Addition-Fragmentation Chemistry in Polymer Synthesis. Polymer 2008, 49, 1079-1131.

(41) Shen, L.; Lu, Q.; Zhu, A.; Lv, X.; An, Z. Photocontrolled RAFT Polymerization Mediated by a Supramolecular Catalyst. ACS Macro Lett. 2017, 6, 625-631.

(42) Hill, M. R.; Carmean, R. N.; Sumerlin, B. S. Expanding the Scope of RAFT Polymerization: Recent Advances and New Horizons. Macromolecules 2015, 48, 5459-5469.

(43) Niu, J.; Lunn, D. J.; Pusuluri, A.; Yoo, J. I.; O’Malley, M. A.; Mitragotri, S.; Soh, H. T.; Hawker, C. J. Engineering Live Cell Surfaces with Functional Polymers via Cytocompatible Controlled Radical Polymerization. Nat. Chem. 2017, 9, 537-545.

(44) Tucker, B. S.; Coughlin, M. L.; Figg, C. A.; Sumerlin, B. S. Grafting-From Proteins Using MetalFree PET-RAFT Polymerizations under Mild Visible-Light Irradiation. ACS Macro Lett. 2017, 6 , $452-457$.

(45) Chiefari, J.; Chong, Y. K. B.; Ercole, F.; Krstina, J.; Jeffery, J.; Le, T. P. T.; Mayadunne, R. T. A.; Meijs, G. F.; Moad, C. L.; Moad, G.; et al. Living Free-Radical Polymerization by Reversible Addition - Fragmentation Chain Transfer: The RAFT Process. Macromolecules 1998, 31, 55595562.

(46) Shanmugam, S.; Xu, J.; Boyer, C. Living Additive Manufacturing. ACS Cent. Sci. 2017, 3, 95-96.

(47) Shanmugam, S.; Cuthbert, J.; Flum, J.; Fantin, M.; Boyer, C.; Kowalewski, T.; Matyjaszewski, K. Transformation of Gels: Via Catalyst-Free Selective RAFT Photoactivation. Polym. Chem. 2019, 10, 2477-2483.

(48) McKenzie, T. G.; Wong, E. H. H.; Fu, Q.; Sulistio, A.; Dunstan, D. E.; Qiao, G. G. Controlled Formation of Star Polymer Nanoparticles via Visible Light Photopolymerization. ACS Macro Lett. 2015, 4, 1012-1016.

(49) McKenzie, T. G.; Fu, Q.; Wong, E. H. H.; Dunstan, D. E.; Qiao, G. G. Visible Light Mediated Controlled Radical Polymerization in the Absence of Exogenous Radical Sources or Catalysts. Macromolecules 2015, 48, 3864-3872.

(50) Yeow, J.; Sugita, O. R.; Boyer, C. Visible Light-Mediated Polymerization-Induced Self-Assembly in the Absence of External Catalyst or Initiator. ACS Macro Lett. 2016, 5, 558-564.

(51) Xu, J.; Shanmugam, S.; Corrigan, N. A.; Boyer, C. Catalyst-Free Visible Light-Induced RAFT Photopolymerization. In Controlled Radical Polymerization: Mechanisms; ACS Symposium Series; American Chemical Society, 2015; pp 247-267.

(52) Jung, K.; Boyer, C.; Zetterlund, P. B. RAFT Iniferter Polymerization in Miniemulsion Using Visible Light. Polym. Chem. 2017, 8, 3965-3970.

(53) Bagheri, A.; Sadrearhami, Z.; Adnan, N. N. M.; Boyer, C.; Lim, M. Surface Functionalization of Upconversion Nanoparticles Using Visible Light-Mediated Polymerization. Polymer 2018, 151, 614.

(54) Pan, X.; Jiang, G.; Zhu, X.; Zhu, J.; Fan, C.; Zhang, Z.; Ding, C. Photocatalyst-Free and Blue LightInduced RAFT Polymerization of Vinyl Acetate at Ambient Temperature. Macromol. Rapid 
Commun. 2015, 36, 2181-2185.

(55) Otsu, T. Iniferter Concept and Living Radical Polymerization. J. Polym. Sci. Part A Polym. Chem. 2000, 38, 2121-2136.

(56) Ligon, S. C.; Husár, B.; Wutzel, H.; Holman, R.; Liska, R. Strategies to Reduce Oxygen Inhibition in Photoinduced Polymerization. Chem. Rev. 2014, 114, 577-589.

(57) Wilson, O. R.; Magenau, A. J. D. Oxygen Tolerant and Room Temperature RAFT through Alkylborane Initiation. ACS Macro Lett. 2018, 7, 370-375.

(58) Enciso, A. E.; Fu, L.; Russell, A. J.; Matyjaszewski, K. A Breathing Atom-Transfer Radical Polymerization: Fully Oxygen-Tolerant Polymerization Inspired by Aerobic Respiration of Cells. Angew. Chemie - Int. Ed. 2018, 57, 933-936.

(59) Gody, G.; Barbey, R.; Danial, M.; Perrier, S. Ultrafast RAFT Polymerization: Multiblock Copolymers within Minutes. Polym. Chem. 2015, 6, 1502-1511.

(60) Li, J.; Ding, C.; Zhang, Z.; Pan, X.; Li, N.; Zhu, J.; Zhu, X. Visible Light-Induced Living Radical Polymerization of Butyl Acrylate: Photocatalyst-Free, Ultrafast, and Oxygen Tolerance. Macromol. Rapid Commun. 2017, 38, 1-8.

(61) McKenzie, T. G.; Fu, Q.; Uchiyama, M.; Satoh, K.; Xu, J.; Boyer, C.; Kamigaito, M.; Qiao, G. G. Beyond Traditional RAFT: Alternative Activation of Thiocarbonylthio Compounds for Controlled Polymerization. Adv. Sci. 2016, 3, 1-9.

(62) Zhang, Z.; Zhu, J.; Cheng, Z.; Zhu, X. Reversible Addition-Fragmentation Chain Transfer (RAFT) Polymerization of Styrene in the Presence of Oxygen. Polymer 2007, 48, 4393-4400.

(63) Reyhani, A.; McKenzie, T. G.; Ranji-Burachaloo, H.; Fu, Q.; Qiao, G. G. Fenton-RAFT Polymerization: An "On-Demand" Chain-Growth Method. Chem. - A Eur. J. 2017, 23, 7221-7226.

(64) Lamb, J. R.; Qin, K. P.; Johnson, J. A. Visible-Light-Mediated, Additive-Free, and Open-to-Air Controlled Radical Polymerization of Acrylates and Acrylamides. Polym. Chem. 2019, 10, 15851590.

(65) Chapman, R.; Gormley, A. J.; Herpoldt, K. L.; Stevens, M. M. Highly Controlled Open Vessel RAFT Polymerizations by Enzyme Degassing. Macromolecules 2014, 47, 8541-8547.

(66) Chapman, R.; Gormley, A. J.; Stenzel, M. H.; Stevens, M. M. Combinatorial Low-Volume Synthesis of Well-Defined Polymers by Enzyme Degassing. Angew. Chemie - Int. Ed. 2016, 55, 4500-4503.

(67) Oytun, F.; Kahveci, M. U.; Yagci, Y. Sugar Overcomes Oxygen Inhibition in Photoinitiated Free Radical Polymerization. J. Polym. Sci. Part A Polym. Chem. 2013, 51, 1685-1689.

(68) Niu, J.; Page, Z. A.; Dolinski, N. D.; Anastasaki, A.; Hsueh, A. T.; Soh, H. T.; Hawker, C. J. Rapid Visible Light-Mediated Controlled Aqueous Polymerization with in Situ Monitoring. ACS Macro Lett. 2017, 6, 1109-1113.

(69) Ren, K.; Perez-Mercader, J. Thermoresponsive Gels Directly Obtained: Via Visible Light-Mediated Polymerization-Induced Self-Assembly with Oxygen Tolerance. Polym. Chem. 2017, 8, 3548-3552.

(70) Xu, J.; Shanmugam, S.; Fu, C.; Aguey-Zinsou, K. F.; Boyer, C. Selective Photoactivation: From a Single Unit Monomer Insertion Reaction to Controlled Polymer Architectures. J. Am. Chem. Soc. 2016, 138, 3094-3106.

(71) Corrigan, N.; Rosli, D.; Jones, J. W. J.; Xu, J.; Boyer, C. Oxygen Tolerance in Living Radical Polymerization: Investigation of Mechanism and Implementation in Continuous Flow Polymerization. Macromolecules 2016, 49, 6779-6789.

(72) Shanmugam, S.; Xu, J.; Boyer, C. Exploiting Metalloporphyrins for Selective Living Radical Polymerization Tunable over Visible Wavelengths. J. Am. Chem. Soc. 2015, 137, 9174-9185. 
(73) Xu, J.; Jung, K.; Atme, A.; Shanmugam, S.; Boyer, C. A Robust and Versatile Photoinduced Living Polymerization of Conjugated and Unconjugated Monomers and Its Oxygen Tolerance. J. Am. Chem. Soc. 2014, 136, 5508-5519.

(74) Xu, J.; Jung, K.; Boyer, C. Oxygen Tolerance Study of Photoinduced Electron Transfer-Reversible Addition-Fragmentation Chain Transfer (PET-RAFT) Polymerization Mediated by $\mathrm{Ru}(\mathrm{Bpy})_{3} \mathrm{Cl}_{2}$. Macromolecules 2014, 47, 4217-4229.

(75) Figg, C. A.; Hickman, J. D.; Scheutz, G. M.; Shanmugam, S.; Carmean, R. N.; Tucker, B. S.; Boyer, C.; Sumerlin, B. S. Color-Coding Visible Light Polymerizations to Elucidate the Activation of Trithiocarbonates Using Eosin Y. Macromolecules 2018, 51, 1370-1376.

(76) Yeow, J.; Chapman, R.; Xu, J.; Boyer, C. Oxygen Tolerant Photopolymerization for Ultralow Volumes. Polym. Chem. 2017, 8, 5012-5022.

(77) Bagheri, A.; Arandiyan, H.; Adnan, N. N. M.; Boyer, C.; Lim, M. Controlled Direct Growth of Polymer Shell on Upconversion Nanoparticle Surface via Visible Light Regulated Polymerization. Macromolecules 2017, 50, 7137-7147.

(78) Gormley, A. J.; Yeow, J.; Ng, G.; Conway, Ó.; Boyer, C.; Chapman, R. An Oxygen-Tolerant PETRAFT Polymerization for Screening Structure-Activity Relationships. Angew. Chemie - Int. Ed. 2018, 57, 1557-1562.

(79) Fors, B. P.; Hawker, C. J. Control of a Living Radical Polymerization of Methacrylates by Light. Angew. Chemie - Int. Ed. 2012, 51, 8850-8853.

(80) Xu, J.; Shanmugam, S.; Duong, H. T.; Boyer, C. Organo-Photocatalysts for Photoinduced Electron Transfer-Reversible Addition-Fragmentation Chain Transfer (PET-RAFT) Polymerization. Polym. Chem. 2015, 6, 5615-5624.

(81) Dadashi-Silab, S.; Doran, S.; Yagci, Y. Photoinduced Electron Transfer Reactions for Macromolecular Syntheses. Chem. Rev. 2016, 116, 10212-10275.

(82) Ciftci, M.; Batat, P.; Demirel, A. L.; Xu, G.; Buchmeiser, M.; Yagci, Y. Visible Light-Induced Grafting from Polyolefins. Macromolecules 2013, 46, 6395-6401.

(83) Zhao, Y.; Zhang, S.; Wu, Z.; Liu, X.; Zhao, X.; Peng, C.-H.; Fu, X. Visible-Light-Induced Living Radical Polymerization (LRP) Mediated by (Salen)Co(II)/TPO at Ambient Temperature. Macromolecules 2015, 48, 5132-5139.

(84) Ohtsuki, A.; Goto, A.; Kaji, H. Visible-Light-Induced Reversible Complexation Mediated Living Radical Polymerization of Methacrylates with Organic Catalysts. Macromolecules 2013, 46, 96102.

(85) Tong, J.; Shi, Y.; Liu, G.; Huang, T.; Xu, N.; Zhu, Z.; Cai, Y. Visible Light Mediated Fast Iterative Raft Synthesis of Amino-Based Reactive Copolymers in Water at $20^{\circ} \mathrm{C}$. Macromol. Rapid Commun. 2013, 34, 1827-1832.

(86) Tasdelen, M. A.; Ciftci, M.; Yagci, Y. Visible Light-Induced Atom Transfer Radical Polymerization. Macromol. Chem. Phys. 2012, 213, 1391-1396.

(87) Zhao, Y.; Yu, M.; Zhang, S.; Liu, Y.; Fu, X. Visible Light Induced Living/Controlled Radical Polymerization of Acrylates Catalyzed by Cobalt Porphyrins. Macromolecules 2014, 47, 62386245.

(88) Anastasaki, A.; Nikolaou, V.; Zhang, Q.; Burns, J.; Samanta, S. R.; Waldron, C.; Haddleton, A. J.; McHale, R.; Fox, D.; Percec, V.; et al. Copper(II)/Tertiary Amine Synergy in Photoinduced Living Radical Polymerization: Accelerated Synthesis of $\omega$-Functional and $\alpha, \omega$-Heterofunctional Poly(Acrylates). J. Am. Chem. Soc. 2014, 136, 1141-1149.

(89) Al Mousawi, A.; Garra, P.; Sallenave, X.; Dumur, F.; Toufaily, J.; Hamieh, T.; Graff, B.; Gigmes, 
D.; Fouassier, J. P.; Lalevée, J. $\pi$-Conjugated Dithienophosphole Derivatives as High Performance Photoinitiators for 3D Printing Resins. Macromolecules 2018, 51, 1811-1821.

(90) Oesterreicher, A.; Wiener, J.; Roth, M.; Moser, A.; Gmeiner, R.; Edler, M.; Pinter, G.; Griesser, T. Tough and Degradable Photopolymers Derived from Alkyne Monomers for 3D Printing of Biomedical Materials. Polym. Chem. 2016, 7, 5169-5180.

(91) Al Mousawi, A.; Dumur, F.; Garra, P.; Toufaily, J.; Hamieh, T.; Goubard, F.; Bui, T. T.; Graff, B.; Gigmes, D.; Pierre Fouassier, J.; et al. Azahelicenes as Visible Light Photoinitiators for Cationic and Radical Polymerization: Preparation of Photoluminescent Polymers and Use in High Performance LED Projector 3D Printing Resins. J. Polym. Sci. Part A Polym. Chem. 2017, 55, 1189-1199.

(92) Zhang, J.; Dumur, F.; Xiao, P.; Graff, B.; Gigmes, D.; Pierre Fouassier, J.; Lalevée, J. Aminothiazonaphthalic Anhydride Derivatives as Photoinitiators for Violet/Blue LED-Induced Cationic and Radical Photopolymerizations and 3D-Printing Resins. J. Polym. Sci. Part A Polym. Chem. 2016, 54, 1189-1196.

(93) Al Mousawi, A.; Dumur, F.; Garra, P.; Toufaily, J.; Hamieh, T.; Graff, B.; Gigmes, D.; Fouassier, J. P.; Lalevée, J. Carbazole Scaffold Based Photoinitiator/Photoredox Catalysts: Toward New High Performance Photoinitiating Systems and Application in LED Projector 3D Printing Resins. Macromolecules 2017, 50, 2747-2758.

(94) Al Mousawi, A.; Garra, P.; Schmitt, M.; Toufaily, J.; Hamieh, T.; Graff, B.; Fouassier, J. P.; Dumur, F.; Lalevée, J. 3-Hydroxyflavone and N-Phenylglycine in High Performance Photoinitiating Systems for 3D Printing and Photocomposites Synthesis. Macromolecules 2018, 51, 4633-4641.

(95) Bagheri, A.; Arandiyan, H.; Boyer, C.; Lim, M. Lanthanide-Doped Upconversion Nanoparticles: Emerging Intelligent Light-Activated Drug Delivery Systems. Adv. Sci. 2016, 3, 1500437.

(96) Nomeir, B.; Fabre, O.; Ferji, K. Effect of Tertiary Amines on the Photoinduced Electron TransferReversible Addition - Fragmentation Chain Transfer (PET-RAFT) Polymerization. Macromolecules 2019, 52, 6898-6903.

(97) Lee, I. H.; Discekici, E. H.; Anastasaki, A.; De Alaniz, J. R.; Hawker, C. J. Controlled Radical Polymerization of Vinyl Ketones Using Visible Light. Polym. Chem. 2017, 8, 3351-3356.

(98) Hu, J.; Wang, J.; Nguyen, T. H.; Zheng, N. The Chemistry of Amine Radical Cations Produced by Visible Light Photoredox Catalysis. Beilstein J. Org. Chem. 2013, 9, 1977-2001.

(99) Zaquen, N.; Kadir, A. M. N. B. P. H. A.; Iasa, A.; Corrigan, N.; Junkers, T.; Zetterlund, P. B.; Boyer, C. Rapid Oxygen Tolerant Aqueous RAFT Photopolymerization in Continuous Flow Reactors. Macromolecules 2019, 52, 1609-1619.

(100) Gorsche, C.; Koch, T.; Moszner, N.; Liska, R. Exploring the Benefits of $\beta$-Allyl Sulfones for More Homogeneous Dimethacrylate Photopolymer Networks. Polym. Chem. 2015, 6, 2038-2047.

(101) Fu, Q.; Xie, K.; McKenzie, T. G.; Qiao, G. G. Trithiocarbonates as Intrinsic Photoredox Catalysts and RAFT Agents for Oxygen Tolerant Controlled Radical Polymerization. Polym. Chem. 2017, 8 , $1519-1526$.

(102) Kizilel, S.; Pérez-Luna, V. H.; Teymour, F. Photopolymerization of Poly(Ethylene Glycol) Diacrylate on Eosin-Functionalized Surfaces. Langmuir 2004, 20, 8652-8658.

(103) Avens, H. J.; Randle, T. J.; Bowman, C. N. Polymerization Behavior and Polymer Properties of Eosin-Mediated Surface Modification Reactions. Polymer 2008, 49, 4762-4768.

(104) Kurek, P. N.; Kloster, A. J.; Weaver, K. A.; Manahan, R.; Allegrezza, M. L.; De Alwis Watuthanthrige, N.; Boyer, C.; Reeves, J. A.; Konkolewicz, D. How Do Reaction and Reactor Conditions Affect Photoinduced Electron/Energy Transfer Reversible Addition-Fragmentation Transfer Polymerization? Ind. Eng. Chem. Res. 2018, 57, 4203-4213. 
(105) Zaquen, N.; Azizi, W. A. A. W.; Yeow, J.; Kuchel, R. P.; Junkers, T.; Zetterlund, P. B.; Boyer, C. Alcohol-Based PISA in Batch and Flow: Exploring the Role of Photoinitiators. Polym. Chem. 2019, $10,2406-2414$.

(106) Konishi, T.; Ikeda, A.; Asai, M.; Hatano, T.; Shinkai, S.; Fujitsuka, M.; Ito, O.; Tsuchiya, Y.; Kikuchi, J. I. Improvement of Quantum Yields for Photoinduced Energy/Electron Transfer by Isolation of Self-Aggregative Zinc Tetraphenyl Porphyrin-Pendant Polymer Using Cyclodextrin Inclusion in Aqueous Solution. J. Phys. Chem. B 2003, 107, 11261-11266.

(107) See, Y.; Cha, J.; Chang, T.; Ree, M. Glass Transition Temperature of Poly ( Tert -Butyl Methacrylate ) Langmuir - Blodgett Film and Spin-Coated Film by X-Ray Reflectivity and Ellipsometry. Langmuir 2000, 16, 2351-2355. 


\section{Graphical Abstract}

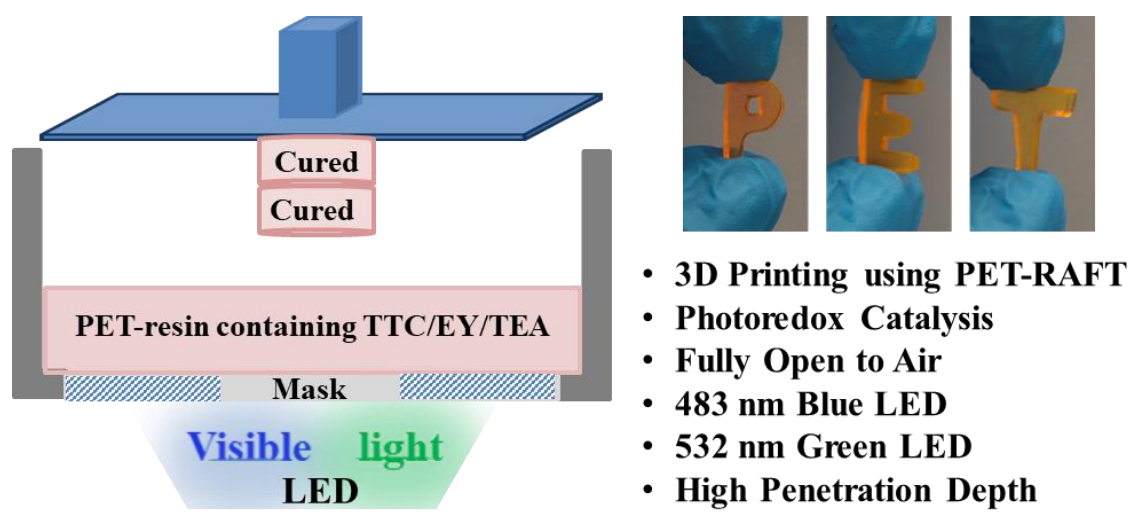

